\title{
Experience of Professional Development Strategies: Context of Nepalese EFL Teachers
}

\author{
Kumari Damayanti Joshi* \\ Laxman Gnawali** $^{* *}$ \\ Mary Dixon $^{* * *}$
}

\begin{abstract}
Professional Development (PD) for teachers in developing countries is an emerging emphasis despite limited resources. Evidence regarding the teachers' experiences of PD activities in developing countries, including Nepal, are not well known. This study aimed to identify and discuss PD strategies employed by Nepalese English as a foreign language (EFL) teachers and experiences. The study employed a qualitative research design for data collection among 45 EFL teachers recruited from 15 high schools and colleges across the districts of Kathmandu and Lalitpur. Data on teachers' age, gender, academic qualification, teaching experience (in terms of number of years), and teacher training, their experiences about PD and the perceived benefits of the different learning strategies of PD were collected using a questionnaire. The findings are presented in terms of the four main groups of PD strategies - self-directed, professionrelated, peer-supported and study-(research-) focused. We report that the Nepalese EFL teachers have positive experience towards different PD strategies. The EFL teachers have been benefited mostly from selfdirected (own teaching experience and self -monitoring), profession related (workshops, seminars and conferences), and peer-supported (learning from colleagues) PD strategies. The study recommends that there is a need for on-going PD activities for EFL teachers in Nepal.
\end{abstract}

Keywords: English language teaching, EFL teachers, learning strategies, Nepal, professional development

\footnotetext{
* School of Education, Deakin University, Australia. Email: zosi.diya@gmail.com ${ }^{* *}$ School of Education, Kathmandu University, Nepal. Email: lgnawali@gmail.com

${ }^{* * *}$ School of Education, Deakin University, Australia.Email: mary.dixon@deakin.edu.au
} 


\section{Introduction}

Professional development (PD) refers to the process that supports individual's improvement in professionalism (Evans, 2008). PD in the context of teachers is an essential process to grow after they commence their professional career and continues until they retire (Richards \& Farrell, 2005; Villegas-Reimer, 2003). Teachers' PD mainly focuses on teachers' learning; learning how to learn, and transforming their knowledge into classroom practices (Avalos, 2011) and taking place in both informal and formal contexts (Ball \&Cohen, 1999). Informal learning constitutes self-practice, reflecting on one's own performance, interacting with colleagues, seeking answers to emerging issues, and reading to keep one-self up-to-date. Formal learning involves pursuing higher education, undertaking teacher training courses, attending workshops, seminars and conferences. Teacher learning has been considered to be a continuous process involving pre-service education, work-place learning and on-going professional learning (DarlingHammond \& Sykes, 1999; Day, 1999). While teacher learning and teacher development refers to the same notion of teacher's PD (Dobson, 2006; Head\& Tylor, 1997; Richard et al., 1998), the various approaches to teachers' PD essentially aims to update and up-skill them in the years beyond their pre-service teacher education programmes (Bolam \& Weindling, 2006). Darling-Hammond and Richardson (2009) argue that such a development in teachers' learning would help improve education system in general.

PD for English as a foreign language (EFL) teachers aims to improve teaching process in order for learners to enhance their English language skills and literacy (Centre for Applied Linguistics, 2010). Furthermore, EFL teachers have an important role to play in improving teaching methodology and quality of education. As the use of English language in various sectors of society, including academic and professional realms, continue to grow; the need of adoption of effective PD strategies for English language practitioners increases.

\section{Framing PD Strategies}

There are various strategies available for PD for teachers, which in fact, are the approaches that are consciously selected by a professional teacher (Cohen, 1998). These PD strategies for EFL teachers have been grouped into different categories. Pfannamstiel et al. (2000) have categorised various teachers' PD strategies into two groups: traditional 
and job-embedded. The former includes workshops, conferences, meetings and courses, whereas the later includes observing demonstration lessons, coaching or mentoring, study groups, reflecting specific classroom practices, action research, planning lessons and sharing of best practices. Similarly, Richards and Farrell (2005) has classified various PD activities into four groups: individual, one-to-one, group-based and institutional. In general, teachers' PD strategies can be classified into four different themes: self-initiated, peer-supported, study(research)-focused, and profession-related (Giri,2015) (Figure 1); based on the available literature (Hoque et al.,2011;Pfannamstiel et al.,2000; Richards \& Farrell, 2005).

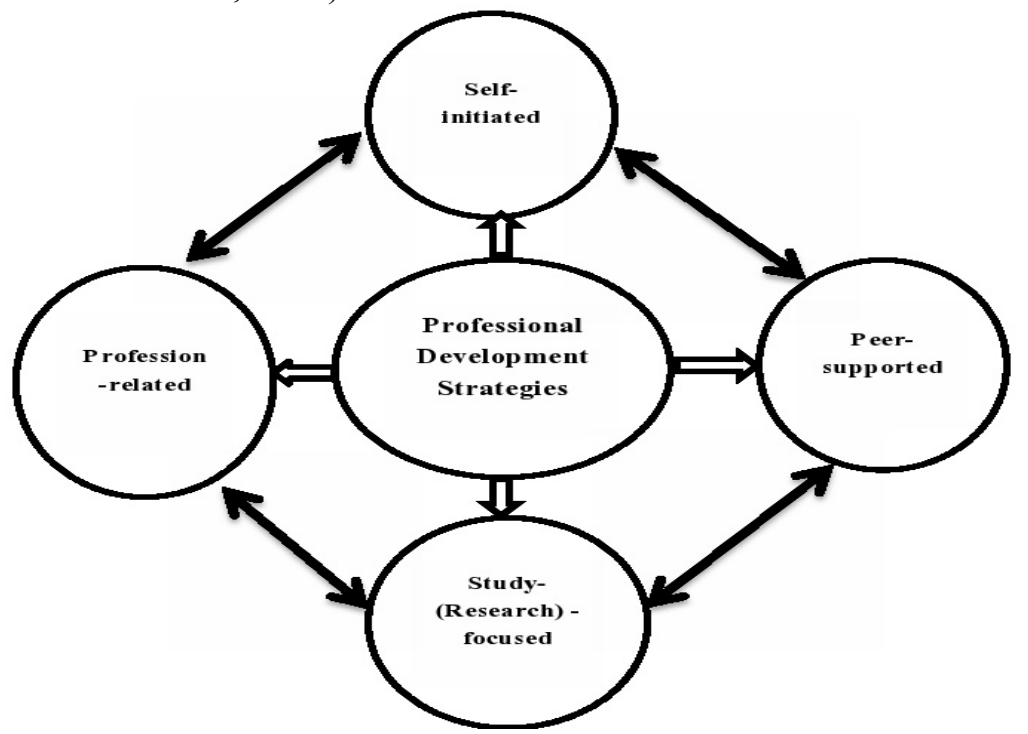

Figure 1: A framework of teachers' professional development strategies (Giri, 2015)

The self-initiated or self-directed PD strategies are those set of selfdevelopmental efforts in which a teacher adopts responsibility for setting goals to manage and control his/her own learning (Richards \& Farrell, 2005). This component of PD strategy includes learning through selfmonitoring, teaching experience, self-study, teaching portfolios, higher degrees, online courses, reflective teaching, reflective logs, refresher courses and so on (Richards \& Farrell, 2005). The peer supported approach is a learning methodology where group-oriented activities with shared goals and responsibilities are performed to enhance individual learning, to solve problems collaboratively, and also to meet the 
collective goals of an organisation (Richards and Farrell, 2005). The examples of the peer supported PD strategies are: learning from colleagues, peer observation, peer coaching, team-teaching, teacher support groups, mentoring, and so on (Richards and Farrell 2005). Similarly, the study (research)-focused PD strategies aim to systematically carry out research that translates into learning practices. Such PD strategies include action research, analysis of critical incidents, ELT journals, case analysis, resource and teacher activity centres (RTACs), publications, and so on (Richards \& Farrell, 2005).

Profession-related PD strategies are generally institutional in-service or job-embedded learning approaches such as workshops, seminars, conferences, and so on, which are meant for continuing professional growth of an individual teacher as well as an institution (Hoque et al.,2011; Richards \& Farrell, 2005). These PD strategies help update teacher's knowledge and skills as the original qualification becomes outdated with time due to the nature of evolving ELT approaches. A few PD strategies described under the above mentioned four PD components are not restrictive only to a single component, for example, analysis of critical incidents, case study or action research can fall into any category. The reason is that some PD activities can be carried out in more than one mode - individual, group or organizational (Richards \& Farrell, 2005).

\section{The Study Context}

\section{Current Education System and EFL Teaching in Nepal}

The planning commission of Nepal has recognised education amongst one of the areas to be improved for achieving sustainable development goals. In view of this, Nepalese education system adopted a long-term School Sector Reform Plans (SSRPs, 2009-2015 and 20162023) to produce the much capable human resources that could help elevate the country's status to a middle-income country by 2030 from its current status of a least developed country (Ministry of Education, 2016). Following the inception of the SSRP (2009-2015), the formal education in Nepal has been structured into three levels: i) basic (primary) education, which comprises schooling up to grade 8 , including one year of early childhood development (ECD)/pre-primary classes (PPCs); ii) secondary education comprising grades 9 to 12 (grades 11 and 12, previously known as higher secondary levels), and iii) higher education comprising bachelor or higher degrees(Ministry of Education, 2016). There are a total of 36,093 ECD/PPCs, 35,222 schools, 13 universities 
(including deemed medical universities), and 1,369 affiliated campuses (Education in Figure, 2016). The number of higher secondary schools numbered 1,976 (66.5\% community run) in 2009/10 (Ministry of Education, 2010a). The universities are community (publicly) funded, whereas the rest of the educational institutes are either publicly or privately-funded. For instance, the proportion of community funded schools and campuses are $83 \%$ and $32 \%$ respectively.

According to the National Education Plan, English has been recognised as an international language at the school level (Ministry of Education, 2013). These days, English is one of the compulsory subjects in schools from grade 1 (Sharma \& Phyak, 2017). Most of the community schools teach school curricula/subjects in Nepali-medium, while all private schools use English as a medium of instruction for teaching (Ministry of Education, 2011; Thapa, 2012). In recent years, a number of community schools have adopted a culture of teaching their curricula/subjects in English medium, mainly due to parental and community preferences. Therefore, Nepal has become a country where a shift from English being taught as a foreign language to English being the medium of instruction (EMI) across all levels of school and university has been taking place (Dearden, 2014). As a result of this, both community and private institutions these days allow EMI from primary to university levels. However, it also adds up linguistic and didactic challenges to education system since an overwhelming majority of community schools teachers are still not adequately qualified to be EMI teachers (Dearden 2014; Ministry of Education, 2016).

With a changing landscape of English language usage in Nepal, the country has been facing a growing demand for quality EFL teachers and teaching practices (Giri, 2010). To illustrate this further, the number of EFL teachers increased from 40, 000 in 2005 (Bhattarai \& Gautam, 2005 ) to 1, 65,552 in 2009 (Ministry of Education, 2010b). However, the country has a considerable number of EFL teachers, including teacher trainers, with inadequate training or qualifications (Shah, 2015). For example, only $22.2 \%$ of EFL teachers $(36,800$ of $1,65,552)$ were reported to be fully trained in 2009 (Ministry of Education, 2010b). These under qualified teachers do not have sound knowledge of English language and competency in English language teaching (Giri, 2010). 


\section{In-service Teachers' PD in Nepal}

\section{Historical Development of Teachers' PD in Nepal}

Teacher education in Nepal started in 1948 with the establishment of Basic Teacher Training Centre, which later evolved into the Normal School in 1956 (Ministry of Education, 2010a). The College of Education was only established in 1956 to start teachers' formal education.

The National Education System Plan (1971-1975) put forward a long-term plan for teacher education, including teacher training. During 1980 s and late 1990s, many projects such as Primary Education Development Project (PEDP), Science Education Development Project (SEDP), Basic and Primary Education Programme (BPEP) and Secondary Education Development Project (SEDP) were implemented to ameliorate the capacity of teachers and schools (Ministry of Education 2010a; Sinha, 2015). Need for teacher education was further highlighted to support teacher development effectively through National Centre for Educational Development (NCED) (National Education Commission, 1992). In 1993, the NCED was therefore established under the Ministry of Education, and became the apex body to provide PD trainings to school teachers. Since then, the NCED has been delivering teacher trainings through its 34 education training centres and 46 learning resource centres across the country (Sinha, 2015).

\section{Recent Development in Teachers' Training}

The School Sector Reform Plan (SSRP, 2009-2015) was the latest accomplished program in Nepalese education sector for school teachers' PD. Until the implementation of the SSRP, most of the teachers' PD programs were one-shot, top-down and decontextualized resulting in a limited effectiveness (Corneli et al., 2015; Rajbhandari et al., 2009). In such context, the SSRP aimed to strengthen the capacity of in-service community primary and secondary school teachers by providing PD trainings to 70,000 teachers and prepare nearly 1,000 trainers (Rajbhandari et al., 2009). As per the SSRP (2009-2015), the NCED conducted teacher trainings for the teachers. A 10-day-long teacher PD training, designed considering teachers' $P D$ needs, was provided to permanent teachers of primary and secondary schools (Ministry of Education, 2013). The NCED developed Teacher Support Mechanism 
and Teachers Development Handbook and Guidelines to implement the SSRP (2009-2015). The training was delivered in three phases:i) face-toface mode training cum workshops (5 days in training centres), ii) selfstudy exercise in schools (3 days) and iii) instructional counselling (2 days) (Corneli et al., 2015). Similar one month PD training was also planned to be provided over three sessions (10 days each) to the teachers over the next five years. The SSRP (2009-2015) also made some important provisions such as job induction training to novice teachers, minimum of 1-month in-service teacher training in every five years and accreditation of teacher trainings. It also recommends one-year of teacher preparation course for the prospective candidates of teachers with educational qualifications other than such as Proficiency Certificate (Intermediate in Education program, I. Ed., now phased out from Tribhuvan University), bachelors or master's in education (Bhomi \& Suwal, 2014). In addition, the SSRP (2009-2015) also provided with some policy guidelines regarding continuous PD programs for teachers. Despite some positive efforts of the government of Nepal to increase the number of teachers receiving PD trainings, the effectiveness of these trainings in classroom teaching was found to be low (Ministry of Education, 2013). As a continuation of the SSRP, the second phase of the SSRP (SSRP 2016-2023) has been recently launched to further strengthen quality school education through improved school-based teachers' PD (Ministry of Education, 2016). Therefore, a long-term implementation of SSRPsis believed to have some positive impacts on the school education system in Nepal through improved teachers' PD programs.

Tribhuvan University runs a one-year Teacher Preparation Course (TPC), which is specially designed for working teachers/candidates with educational qualification of grade 12 or equivalent degree. Teachers' professional associations also contribute partly to teachers' PD activities. For instance; in the context of EFL teachers, the Nepal English Language Teachers' Association (NELTA) is an important organisation to support EFL teachers' PD. In particular, it creates opportunities for professional networks, organizes conferences/workshops/seminars, and updates EFL teachers on EFL teaching related issues via its blogzine, a newsletter and a peer-reviewed journal (Gnawali, 2016). Similarly, some external or non-governmental organisations, such as British Council Nepal, American Embassy, and Rural Education and Environment Development Centre, etc., also contribute to EFL teachers' PD programs (Shah, 2015).

A limited opportunities/support is available for the teachers, and there is lack of adequate governmental financial support from institutions to 
provide systematic on-going PD programs (Timilsina, 2014). Further, Nepal witnesses a positive development regarding teachers' PD programs in recent years, systematic studies investigating teachers' issues related to PD are lacking. For instance, there have been a few PD initiatives for Nepalese EFL teachers, but there is a knowledge gap regarding their issues of their PD (Adhikari, 2011; Dixon, Mayer \& Joshi, 2016; Pokhrel \& Behera, 2016; Shah, 2015). In particular, there is dearth of information regarding what PD strategies do EFL teachers apply for their PD, and what are their attitudes towards those strategies.

\section{Study Aim}

As discussed earlier, PD for teachers in Nepal has been gaining some interest in educational system. However, it is largely unknown that what are different learning strategies adopted by Nepalese teachers and what are their experiences towards them. The aim of this study was to provide an insight into PD strategies employed by Nepalese EFL teachers and discussing their experiences in relation to those PD strategies.

\section{Methodology}

\section{Participants}

This analytical study was conducted in 2010 involving EFL teachers teaching in higher secondary/college level in Kathmandu valley (Kathmandu and Lalitpur districts). All the participants were non-native speakers of English, teaching English as a foreign language. Firstly, 15 institutes - six public and nine private higher secondary schools and colleges - were selected using non-random purposive sampling method in order to include the institutes from different parts of Kathmandu valley. The principals of the schools/colleges were then approached in person to explain about the study purpose and requested to help the researcher in recruiting three EFL teachers from each school/college. Following the approval from the principal of each participating school/college, three EFL teachers from each school/college were conveniently recruited for the study. The participation to the study was voluntary. A total of 45 teachers participated in the study. Verbal consents were taken all the participants. Ethical approval was granted by the relevant institutional ethics committee. The study received approval 
from the Central Department of Education, Tribhuvan University Research Ethics Committee.

\section{Data Collection Procedure}

The study used a qualitative research design of data collection. Quantitative data were also collected to support the qualitative data. The questionnaire was developed based on the available literature (Richards \& Farrell 2005; Soproni, 2007; Sultana, 2004). The questionnaire was piloted among nine EFL teachers in order to validate it.

Each participant was provided with a questionnaire, along with an explanatory letter detailing about the study. The questionnaire was also prefaced by definitions of the 17 different leaning strategies discussed in the abovementioned literature. The questionnaire consisted of three key sections. Participants' information such as age, gender, academic qualification, teaching experience (in terms of number of years), and teacher training were collected in the first section. The second section consisted of eight open ended questions to collect participants' experiences such as perceived benefits of the aforementioned learning strategies of PD. The following eight questions lead the research:

1. What do you understand by 'professional development'?

2. How did you get into English language teaching?

3. Do you think an EFL teacher need to know about various teacher development strategies? Why?

4. What is your opinion about being observed by your colleagues in a class?

5. Are you benefited from teacher support groups, team teaching, mentoring? If yes, what kind of benefits do you get from each of them?

6. Do you have experience of learning from your own teaching experience, self-monitoring case analysis, critical incidents, teaching portfolios or reflective logs? If yes, how have you been benefited from them?

7. Do you have any access to any ELT journals, resource and teacher activity centres? If yes, how have you been benefited from them?

8. Do you participate in workshops, seminars and conferences? If yes, what benefits have you got from each of them?

The first three questions were mainly asked to build a rapport with the participants. The questionnaire sheet provided enough space for each question to include the participants' opinions. The third section of the 
questionnaire consisted of close ended items regarding the PD strategies (see Appendix A). The purpose of the close-ended items was to identify how the teachers learnt from the given PD strategies during their career and what their attitude was towards the strategies. All participants completed the questionnaire and the first author collected them after a week.

\section{Data Analysis}

First of all, the information collected from the open ended questions (i.e. qualitative data) was analysed using thematic analysis. The approach involved three steps:i) reading and identifying possible categories, ii) categorising and interpreting, and iii) visualising and representing (Fan Tang, 2002). The data was then clustered around the four main themes of the PD strategies: self-initiated, peer-supported, study-(research)focused, and profession-related; and thematic analysis was then performed accordingly. All written comments of the participants were content analysed by hand.

The data of the EFL teachers; teachers' age, academic qualification, work experience, teacher training, type of institutes they worked, as well as the teachers' responses to the closed ended items (i.e. quantitative data) were recorded into the Microsoft Excel 2010 and descriptive analysis was performed to compute frequencies and percentages. The socio-demographic information was used with qualitative data, wherever required.

All findings (quantitative and qualitative) of the study were presented together under the four themes of the PD strategies as illustrated in Figure 1.

\section{Findings}

\section{Participants' Characteristics}

Teachers' key characteristics are summarised in table 1 below. Sixty per cent of the teachers $(n=27)$ were reported to have no experience of any additional formal teacher training. The distribution of the number of years of teachers' experience in teaching was as; 14 had $<5$ yrs, 24 had 5-8 yrs, and 7 had $>10$ yrs of experience. The findings showed that 14 were novice teachers, whereas 34 were experienced teachers. The teaching experience of more than five years has been regarded as the 
duration to refer to be an 'experienced teacher' (Richards and Tang, 1998; Soproni, 2007; Tsui, 2005).

Table 1

Teacher Participants' Characteristics $(n=45)$

\begin{tabular}{|c|c|}
\hline Characteristics & Number \\
\hline Age & $\begin{array}{l}\text { median: } 31 \text { years; range: } 25-56 \\
\text { years }\end{array}$ \\
\hline \multicolumn{2}{|l|}{ Gender } \\
\hline Male & 41 \\
\hline Female & 4 \\
\hline \multicolumn{2}{|l|}{ Qualifications } \\
\hline MEd (English Language Teaching) & 16 \\
\hline MA (English literature) & 13 \\
\hline MPhil \& MA (English) & 4 \\
\hline MEd \& MA (English) & 3 \\
\hline MPhil & 2 \\
\hline $\mathrm{PhD}$ & 1 \\
\hline \multicolumn{2}{|l|}{ Type of school } \\
\hline Private & 28 \\
\hline Public & 17 \\
\hline Teaching experience & median $=6$ years; range: $1-36$ years \\
\hline
\end{tabular}

\section{Teachers' Experiences and Attitudes}

The teachers' experiences and attitudes towards various PD strategies are summarised below into the four main themes (categories): self-initiated, peer-supported, study (research)-focused, and profession- 
related. The findings of the qualitative data showed that the participants had a broad understanding of PD, which are represented below in terms of their representative quotes. When asked to explain what PD meant to them, participants' had fairly similar responses. One of the participants opined:

Professional development is a growth process that occurs during a teacher's professional career. (a 36-year old male participant, $>10$ years of experience, public institute)

Two other participants ( 28 -year male, $<5$ years of experience, private institute; and 31-year old male, 5-8 years of experience, private institute) also seconded to this. Furthermore, another participant said:

Professional development is an on-going learning process in which a professional voluntarily engages to learn further. (a 32year old female participant, 5-8 years of experience, private institute)

Similarly, giving his view about PD, a participant said: Professional development for an English Language Teacher is important throughout the practice of teaching in schools and colleges as it makes aware of innovative teaching skills and techniques. (a 40-year old male, $>10$ years of experience, public institute)

Two other participants ( 28 -year male, $<5$ years of experience, private institute; and 31-year old male, 5-8 years of experience, private institute) also seconded to this. Furthermore, another participant said:

Professional development is an on-going learning process in which a professional voluntarily engages to learn further. (a 32year old female participant, 5-8 years of experience, private institute)

Similarly, giving his view about PD, a participant said:

Professional development for an English Language Teacher is important throughout the practice of teaching in schools and colleges as it makes aware of innovative teaching skills and techniques. (a 40-year old male, >10 years of experience, public institute)

Most of the teachers reported that they came into ELT profession mainly because of two reasons: i) self-motivation and interest in English language, and ii) prospects of a good professional career. All the 
participants agreed that they needed to know about various PD strategies applicable to an English language teacher. Furthermore, the participants believed that the knowledge of different PD strategies provided them an opportunity to become more competent with improved teaching skills.

Teachers also provided varied opinions about various PD strategies. We have presented the views, along with the findings of quantitative data, below under the four themes of PD (figure 2).

\section{Self-initiated PD}

The largest number of teachers $(n=43)$ agreed that they learnt from their own experience. However, two teachers disagreed with it. Regarding learning from one's own experience, one of the participants said:

I have learnt more from my own teaching experience than from the courses of study provided in our educational programs I have attended so far... (a 34-year old male, 5-8 years of experience, public institute)

Similarly, another participant shared:

I always keep an eye on my classroom activities... what worked very well and what didn't work at all and keep on improving in this way... (a 35-year male, 5-8 years of experience, private institute)

Thirty eight teachers agreed that they had learnt from selfmonitoring, whereas seven teachers partially agreed about it. Similarly, 12 participants agreed, 24 disagreed and nine partially agreed with the idea of leaning from refresher courses. Furthermore, ten participants agreed, 19 disagreed and 16 partially agreed that reflective logs helped them to improve their professional practice. One of the participants shared his view about the usefulness of reflective logs as

Reflective logs help us to use our previous classroom experience in the future ones and analyse different problems of the class room practices ...the logs may also assist teachers in acquiring new knowledge and skills to become more confident while presenting the subject matter in a classroom. (a33-year old male, $<5$ years of experience, private institute)

Ten teachers agreed, 24 disagreed while 11 partially agreed with the view that teaching portfolios could be valuable in one's PD. One of the participants explained the importance of teaching portfolio as:

Teaching portfolios can help us learn from different works of the experienced teachers....these methods could help us to render on 
our activities and modify them in terms of teachers' needs. (a 29year male, $<5$ years of experience, private institute)

\section{Peer-supported PD}

Thirty participants agreed while 15 partially agreed that they had learnt from their colleagues. Similarly, twenty eight teachers agreed, while 17 partially agreed that they could get new ideas from team teaching. Twenty seven teachers agreed and 18 teachers partially agreed that peer observation might provide an opportunity to learn more. One of the participants mentioned about peer observation as:

Peer observation makes us learn our strengths and weaknesses, which in turn helps us in improving teaching practices...it is helpful for both teachers, who is being observed and who is observing the class, to improve his/her overall performance... but, most of the teachers refuse being observed by their colleagues. (a 31-year male, $<5$ years of experience, private institute)

Similarly, another participant shared his view about learning from colleagues:

Collaborative learning matters - I have been always benefited from my colleagues.... whenever we have leisure time, we discuss about our classroom challenges and practices and learn from each other's teaching experiences. (a 37-year old male, $>10$ years of experience, public institute)

Eleven participants agreed, six disagreed and 28 partially agreed that support groups can be helpful to grow professionally. Five participants agreed, 27 disagreed and 13 partially agreed that they were benefitted from their mentor teachers. One of the participants mentioned her view on mentoring as:

I think mentoring could play a vital role in our development; however, it is very difficult to get mentorship as senior teachers seem always busy. (a 28-year old female, $<5$ years of experience, private institute) 


\section{Study- (research)-focused PD}

Fourteen teachers agreed, 20 partially agreed and 11 teachers disagreed that case analysis could help a teacher to find different solutions for a problem regarding teaching learning process. Similarly, 13 teachers agreed, 24 disagreed and eight partially agreed that they had learnt from analysis of critical incidents. One of the participants said:

Analysing critical incidents in fact helped me to cope with different classroom situations and problems. (a 48-year old male, $>10$ years of experience, private institute)

Twenty four teachers agreed, two disagreed and 19 partially agreed that ELT journals could be beneficial for a teacher's professional development. Similarly, 12 teachers agreed, 24 disagreed and nine partially agreed that resource and teacher activity centres (RTACs) had a positive influence in their professional career. One of the participants opined about RTACs as:

Resource and teacher activity centres provide us different teaching materials like reference books, workbooks, story books, journals, etc., which are practically applicable in our teaching practice thereby providing us an opportunity to widen our professional knowledge and networks. (a 32-year old male, 5-8 years of experience, public institute)

\section{Profession-related PD}

Thirty six teachers agreed and nine partially agreed that they had learnt from the workshops they attended. Similarly, 31 teachers agreed, while 14 disagreed that they were benefited from the seminars they attended. Furthermore, 36teachers agreed, one disagreed and eight partially agreed that they had learnt new things from the conferences they attended. The participants shared their views on these approaches of PD as:

Workshops help us acquire specific knowledge and skills, and provide ideas for improving our classroom practices. (a 29-year old male, $<5$ years of experience, private institute)

"Seminars provide a healthy environment to discuss ELT practices, challenges and classroom problems. (a 35-year old male, 5-8 years of experience, private institute) 
Conferences boost our confidence and make teaching learning process more effective.... It brings different professionals together to discuss appropriate solutions of different problems related to classroom teaching. (40-year old male, $>10$ years of experience, public institute)

Figure 2 presents the results of quantitative data, which are also grouped into the four PD themes.

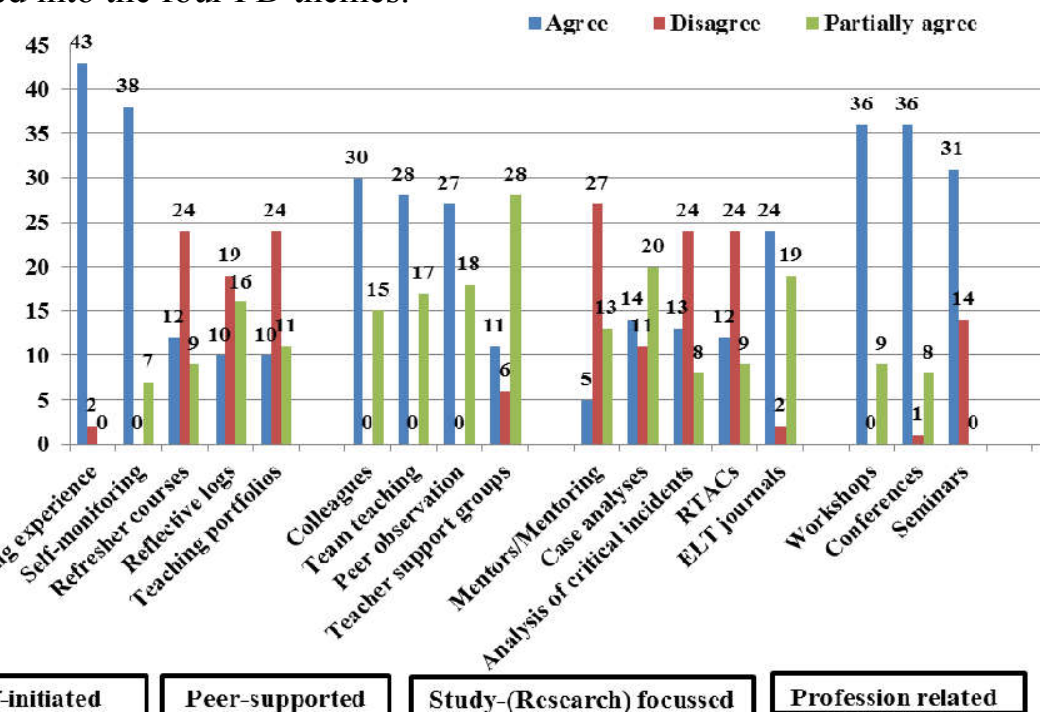

Figure 2: Teachers Vs their attitudes on PD Strategies

Figure 2: The number of teachers (total $n=45$ ) vs. their attitudes towards the usefulness of various PD strategies in terms of the responses; agree, disagree and partially agree, provided to the closed ended items (Appendix). The PD strategies are grouped into the four PD themes (illustrated in figure 1), each PD strategy is characterised with three responses in different colours; the number mentioned on the top of each bar shows the number of teachers providing the given responses.

\section{Discussion}

The present study draws on findings on common PD strategies adopted by Nepalese EFL teachers and their experiences of various PD strategies. The findings largely reflect the participants' experience about PD strategies based on their personal experiences and knowledge. 
However, due to small sample size of the study, interpretation of the results should not be generalised to Nepalese EFL teachers in general.

Teachers' experience in relation to various PD strategies seem to be influenced mainly by their pre-service teaching training. A candidate having Masters of Education in ELT or Masters of Arts majoring in English is eligible to become an EFL teacher for higher secondary or college level. The study found that most of the teachers were experienced, however, they lacked additional PD trainings. One of the reasons for insufficient PD trainings for EFL teachers' in developing countries is heavy emphasis on pre-service education and budget limitations (Komba \& Nkumbi, 2008; Leu, 2004). This also applies in Nepalese EFL teachers' context as they primarily learn teaching techniques and approaches during pre-service courses, however there is challenge to translate these skills into classroom teaching (Shah, 2015).

The teachers apparently used various approaches for their PD. They seemed to be developing professionally mainly through their own teaching experience, self-monitoring, workshops, seminars, conferences, and peer/colleagues. Similar situation of PD among English immersion teachers has been observed in China (Song \& Cheng, 2011). In Nepal, teachers appear to be mostly dependent on self-directed mode of PD such as their own teaching experience, self-monitoring, self-observation, and reflection to develop professionally. The NCED also mentions selfsupported PD as one of the main approaches of teacher development in Nepal (Ministry of Education, 2013; Pokhrel \& Behera, 2016).Teachers' development through self-initiated approach such as self-monitoring finds its commonplace especially among the teachers in developing countries where other learning possibilities are compromised (Dayoub \& Bashiruddin, 2012; Mushayikwa \& Lubben, 2009). Generally, selfinitiated PD strategies are bottom-up approaches to teacher development and are characterised by one's own interest and motivation (Lee \& Kim, 2016). Shah (2015) also concluded that Nepalese EFL teachers seem to be self-motivated and are in search of opportunities for their PD.Many participants of this study acknowledged that collaborative work and observation are useful if realised by team teaching and peer observation. The evidence from developing country like Bangladesh suggests that school improvement can be achieved if schools put much emphasis on teachers' collaboration, in-service training and classroom observation (Hoqueet al., 2011).

Profession-related PD activities such as workshops, seminars and conferences have been very popular approach to PD. Similar findings have been reported while surveying secondary school EFL teachers in 
other region of Nepal(Bharati \& Chalise, 2017). The NELTA has been proactive in organising ELT conferences, workshops and seminar nationally and regionally. Having its operational branches in 42 (out of 75) districts across the country, it also collaborates and coordinates with other governmental and non-governmental organisations to support PD activities for EFL teachers. A majority of the teachers opined these PD activities were beneficial to them. The main reason for this could be that many participants were able to participate in such activities as most of them are conducted in urban settings. However, these urban-centred PD activities may not offer much benefit to the teachers working in rural settings (Shah, 2015). Furthermore, not all institutes, particularly with low resources, may encourage their teachers to attend such PD activities. The reason for this are, firstly, institutes might be hesitant to support their teachers with registration fee, travel and accommodation required for workshops/conferences/seminars, secondly, they would be understaffed while someone attends these sessions thereby adding extra load to other teachers. Availability of resources and academic environment are amongst key determinants of teachers' PD programs (Fisher \& Fraser, 1991). A typical problem seen in terms of EFL teachers PD in developing countries is lack of financial resources (Komba \& Nkumbi, 2008; Leu, 2004). In Nepal, a small survey found that a majority of EFL teacher seem to lack institutional support for their PD (Shah, 2015). A study from Tanzania shows that teachers are rarely supported by schools to attend workshops and seminars (Komba \& Nkumbi, 2008).

Another striking finding of the study is that only a few participants agreed about learning from mentoring, indicating under utilisation of mentoring amongst in-service teaching practice in Nepal. A study conducted by the National Centre for Education Statistics in the US amongst more than five thousand teachers showed that mentoring was least likely to be in practice (Prasadet al., 2001). This approach seems to be limited until the time when one undergoes university training prior to become an EFL teacher. Mentoring has been found to be useful particularly for novice teachers (Mann \&Tang, 2012).Further effort is therefore necessary to boost the potential scope of mentoring in Nepalese context. As per the plans of the SSDP (2016 - 2023), the scope of mentoring will be explored and strengthened as one of the key approaches to PD (Ministry of Education, 2016).

Similarly, a few participants had a positive attitude towards teaching portfolios and most of them were not sure about its benefit in PD. Though $40 \%$ secondary school EFL teachers use it sometimes, only $10 \%$ of them often receive benefit from using it for learning (Bharati \& 
Chalise, 2017). This may be the case because this particular approach is largely unknown and has not been in practice in Nepal. The participants in our study, therefore, seem to rely on the definition of teaching portfolio to make their judgement towards its potential benefit. Similar situation has been noticed in the Netherlands among the teachers at higher education level; majority of teachers shared their positive attitude towards the use of teaching portfolios, but less than a quarter of them had been actually using it (De Rijdtet al., 2006). Similarly, Nakata (2016) suggests that a gap exists between EFL teachers' perceived importance and their actual use of PD strategies in Japan.

There is no mandatory provision of PD for higher secondary/college level EFL teachers in Nepal. The teachers, therefore, seem to be largely unaware of the potential use of many of the PD activities (Bharati \& Chalise, 2017), and they only occasionally get institutional support for undertaking such activities. This is likely due to many reasons, including limited resources available for individual teacher and organisation. According to Postholm (2016), individual and organisational factors affect teachers' involvement in PD activities. Since these factors also have implications for teachers' PD activities in Nepal, educational policies should address these issues in order to support EFL teachers' ongoing PD activities. The School Sector Development Plan 2016 2023 aims to strengthen capacity for continuous PD of teachers through various approaches of PD (Ministry of Education, 2016).

It is expected that the findings of this study could be useful for future research and development in relation to teachers' PD programs in Nepal. Further studies are needed to explore Nepalese EFL teachers' PD needs, existing disparities between the delivery of PD programs and their utilisation by the teachers in classroom, and PD-associated challenges. A Nepalese survey of teachers indicated that teachers are more likely to be motivated towards their PD when it addresses their needs for learning (Pokhrel \& Behera, 2016). In relation to this, our group surveyed Nepalese EFL teachers' perceived PD needs and interests in 2016 (Dixon, Mayer \& Joshi, 2016a), and also collected information from focus group discussions among EFL teachers, teacher trainers, governmental and non-governmental stakeholders in Nepal. The preliminary results of the study suggest that there is a need-based, personalized and ongoing PD program for EFL teachers in Nepal (Joshi, Gnawali, Giri, Dixon, \& Mayer, 2016b). Data analysis of the survey and the focus group discussion are underway, and the findings of this project are expected to inform EFL teachers, teacher trainers, and educational policy makers regarding Nepalese EFL teachers' PD needs and 
challenges. We suggest that future development in EFL teachers' PD programs in Nepal should attempt to develop and implement a locally suitable and result-oriented model of PD rather than directly adopting any PD model from developed countries. A well-designed and implemented PD should be considered an indispensable part of a comprehensive system of teaching and learning that supports students' learning and competencies needed in the 21st century (DarlingHammond, Hyler, \& Gardner, 2017).

\section{Conclusion}

The findings of this study indicate that Nepalese EFL teachers have positive experience towards different PD strategies. Furthermore, the teachers have been benefited mostly from self-directed (own teaching experience and self-monitoring), profession-related (workshops, seminars and conferences) and peer-supported (learning from colleagues) PD strategies. The findings also suggest that there is a potential need for ongoing need-based PD activities for EFL teachers in Nepal.

The study highlights the fact that some learning strategies have been found to have limited preference (such as mentoring) over others. This needs further examination as to why this is so and how all potentially useful learning strategies for EFL teachers could be optimally applicable to enhance their learning and teaching experience. The findings of this study, however, cannot be generalised to entire EFL teachers in Nepal due to its small sample size and limited to the teachers in Kathmandu valley. Therefore, further study including a larger number of teachers, including those from rural schools, is recommended. Such studies will be important basis for making an evidence-based EFL language policy for Nepal. 


\section{References}

Adhikari, M. (2011). Teacher development in the EFL contexts: Principles and strategies (book review). Journal of Nepal English Language Teachers' Association NELTA, 16, 133-135.

Avalos, B. (2011). Teacher professional development in teaching and teacher Education over ten years. Teaching and Teacher Education, 27, 10-20.

Ball, D., \& Cohen, D.K. (1999). Developing practice, developing practitioners: Toward a practice-based theory of professional education. In L.D. Hammond and G. Sykes (Eds.), Teaching as a learning profession: Handbook of policy and practice. (pp. 3-32). San Francisco: Jossey-Bass.

Bharati, P.L., \& Chalise,S. (2017). Teacher Development: Strategies and Perception. The Saptagandaki Journal, 8, 69-78.

Bhattarai, G.R., \& Gautam, G.R. (2005). English Language Teachers at the Crossroads. Journal of Nepal English Language Teachers' Association NELTA, 10(1-2).

Bhomi, A.L., \& Suwal, R. (2014). Teacher Management and Development in Federal System of Government in Nepal. In A Resource Material on Education and Federalism in Nepal. Retrieved from http://unesdoc.unesco.org/images/0023/002309/230932e.pdf

Bolam, R., \& Weindling, D. (2006). Synthesis of research and evaluation projects concerned with capacity-building through teachers' professional development. London: General Teaching Council.

Centre for Applied Linguistics (2010). Framework for quality professional development for practitioners working with adult English language learners. Washington, DC: p7:Center for Adult English Language Acquisition (CAELA) Network Center for Applied Linguistics.

Cohen, A.D. (1998). Strategies in learning and using a second language. Harlow: Longman.

Corneli, M., Rijal, R. R., Gautam, G.R., \& Pandey, S.B. (2015). The Praxis of Collaborative Teacher Development in Nepal. Retrieved from http://carla.umn.edu/conferences/past/LTE2015/docs/Corneli RijalGautamPandey.pdf 
Darling-Hammond, L., \& Sykes, G. (1999). Teaching as the learning profession: handbook of policy and practice. San Francisco, CA: Jossey Bass Publishers.

Darling-Hammond, L., \& Richardson, N. (2009). Teacher learning: what matters? Educational Leadership, 66(5), 46-53.

Darling-Hammond, L., Hyler, M. E., Gardner, M. (2017). Effective Teacher Professional Development. Palo Alto, CA: Learning Policy Institute.

Day, C. (1999). Developing teachers: the challenges of lifelong learning. London: Falmer Press.

Dayoub, R., \& Bashiruddin, A. (2012). Exploring English-language teachers' professional development in developing countries: cases from Syria and Pakistan. Professional Development in Education, 38(4), 589-611.

De Rijdt, C., Tiquet, E., Dochy, F., \& Devolder, M. (2006). Teaching portfolios in higher education and their effects: An explorative study. Teaching and Teacher Education, 22, 1084-1093.

Dearden, J. (2014). English as a medium of instruction - a growing global phenomenon. British Council. Retrieved from https://www. britishcouncil.org/sites/default/files/e484_emi_-_cover_option_3_ final_web.pdf

Dixon, M., Mayer, D., \& Joshi, K.D. (2016a). Professional development landscapes. The Proceedings of the first International Conference on Transformative Education Research and Sustainable Development, Dhulikhel, Nepal, October 21-23, 2016.

Dobson, G. (2006). Teacher development - How to do it. In M. Nikolov, and J. Horváth (Eds.), Empirical studies in English applied linguistics (pp.307-327). Pécs: Lingua Franca Csoport.

Education in Figures (2016). Ministry of Education, Government of Nepal. Retrieved from http://www.moe.gov.np/article/711/nepaleducation-in-figure-2016.html

Evans, L. (2008). Professionalism, professionality and the development of education professionals. British Journal of Educational Studies, 56(1),20-38.

Fan Tang, S.Y. (2002). From behind the pupil's desk to the teacher's 
desk: A qualitative study of student teachers' professional learning in Hong Kong. Asia-Pacific Journal of Teacher Education, 30, 51-65.

Fisher, D.L., \& Fraser, B.J. (1991). School climate and teacher professional development. South Pacific Journal of Teacher Education, 19(1), 17-32.

Gnawali, L. (2016). English language teacher development through teacher associations: the case of NELTA. ELT Journal, 70(2), doi:10.1093/elt/ccv086.

Giri, R. A. (2010). English language teachers' resource centre: A model for developing contexts. Journal of Nepal English Language Teachers' Association NELTA, 15,(1-2).

Giri, R. A. (2015). On professional development of ESL/EFL teachers (personal communication on $6^{\text {th }}$ June, 2015).

Head, K., \& Taylor, P. (1997). Readings in teacher development. Oxford: Heinemann.

High Level National Education Commission, (1998). High Level National Education Commission Report. Ministry of Education, Nepal.

Hoque, K.E. Alam G. M., \& Abdullah, A.G.K. (2011). Impact of teachers' professional development on school improvement-an analysis at Bangladesh standpoint. Asia Pacific Education Review, $12,337-348$.

Joshi, K.D., Gnawali, L., Giri, R.A., Dixon, M., Mayer, D. (2016b). Professional development needs of English \& Teachers in Nepal. The Proceedings of the first International Conference on Transformative Education Research and Sustainable Development, Dhulikhel, Nepal, October 21-23, 2016.

Komba, W.L., \& Nkumbi, E. (2008). Teacher professional development in Tanzania: perceptions and practices. Journal of International Cooperation in Education, 11(3), 67-83.

Lee, J.H., \& Kim, H. (2016). Implementation of SMART teaching 3.0: Mobile-Based Self-Directed EFL teacher professional development. The Journal of Asia TEFL, 13(4), 331-346.

Leu, E. (2004). The patterns and purposes of school-based and cluster teacher professional development programs (EQUIP1 Working Paper No. 2). Washington, DC: USAID. Retrieved from 
http://www.equip123.net/docs/Working-p2.pdf

Mann, S., \& Tang, E.H.H. (2012). The role of mentoring in supporting novice english language teachers in Hong Kong. TESOL Quarterly, 46(3), 472-495.

Ministry of Education (2010a). Ministry of Education: A glimpse 2010. Ministry of education monitoring, evaluation and supervision division research and education management information section (REMIS), Kathmandu, Nepal.

Ministry of Education. (2010b). Nepal: The country context. Ministry of Education and Sports, Government of Nepal.

Ministry of Education. (2011). Retrieved from http://www.ncf.org.np/ upload/files/1007_en_Consolidated\%20Report $\% 202068 \% 20(\% 2020$ 11)_1346397795.p.pdf

Ministry of Education (2013). Teachers' professional development handbook 2066 (in Nepali). National Centre for Educational Development, Sanothimi, Bhaktapur, Nepal.

Ministry of Education. (2016). School sector development plan, Nepal, 2016-2023. Kathmandu: Ministry of Education, Government of Nepal. Retrieved from http://www.moe.gov.np/article/535/schoolsector-development-plan.html

Mushayikwa, E., \& Lubben, F. (2009). Self-directed professional development - hope for teachers working in deprived environments? Teaching and Teacher Education, 25(3), 375-382.

Nakata, Y. (2016). Teachers' readiness for promoting learner autonomy: A study of Japanese EFL high school teachers. Teaching and Teacher Education, 27, 900-910.

National Education Commission (1992). National Education Commission Report. Ministry of Education, Nepal.

National Center for Educational Development (NCED). (2066 BS). Teachers professional development (TPD) handbook-2066. Sanothimi, Bhaktapur, Nepal.

Pfannamstiel, J., Seltzer, D., Yarnell, V., \& Lambson, T., et al. (2000). Study of professional development practices and early childhood education. In Kansas, Kansas State Department of Education, Kansas. 
Pokhrel, T.R., \& Behera, S.K. (2016). Expectations of teachers from teachers professional development program in Nepal. American Journal of Educational Research, 4(2), 190-194.

Postholm, M.B. (2016). Teachers' professional development: a theoretical review. Educational Research, 54(4), 405-429.

Prasad, B., Lewis, L., \& Farris, E. (2001). Teacher preparation and professional development. Education Statistics Quarterly, 3(3), 33-36.

Rajbhandari, P., Kafle, A. P., KC, R., Joshi, S., \& Shrestha, K. (2009). Exploring the opportunities for professional development of primary school teachers in Nepal. Formative Research Project. Study Report 36. Tribhuvan Univerity. Research Centre for Educational Innovation and Development (CERID).

Richards, J.C., Li, B., \& Tang, A. (1998). Exploring pedagogical reasoning skills. In JC Richards (Ed), Beyond training: Perspectives on language teacher education. (pp. 86-102). New York: Cambridge University Press.

Richards J.C., \& Farrell, T.S.C. (2005). Professional development for language teachers - strategies for teacher learning. New York: Cambridge University Press.

Shah, P. K. (2015). Nepalese EFL teachers' professional development: present practices, realities and looking forward. IATEFL Teacher Development SIG Newsletter, 73, 15-17.

Sharma, B. K., \& Phyak, P. (2017). Criticality as ideological becoming: developing english teachers for critical pedagogy in Nepal. Critical Inquiry in Language Studies, doi: 10.1080/15427587.2017.1285204

Sinha, R. S. (2015). Teacher educators for teacher professional development. Teacher Education, 20(72), 269-277.

Song, X., \& Cheng, L. (2011). Investigating primary English immersion teachers in China: background, instructional contexts, professional development, and perceptions. Asia-Pacific Journal of Teacher Education, 39(2), 97-112.

Soproni, Zs. (2007). The Way teachers of English learn: Professional development: Through the eyes of novice and experienced teachers. In J. Horvath and M. Nikolov (Eds.), UPRT 2007: Empirical studies in English applied linguistics, (pp.55-74) Pecs, L. r cosport. 
Sultana, N. (2004). Need assessment a model for professional development of college teachers in Pakistan. An unpublished PhD Thesis: Arid Agriculture, Rawalpindi.

Thapa, A. (2012). Public and private school performance in Nepal: an analysis using the SLC examination. Education Economics, 23, 4762.

Timilsina, B.K. (2014). Teacher professional development at public campuses in Nepal. Unpublished Master Thesis. Retrieved from https://www.researchgate.net/publication/277306052_Teacher_Profe ssional_Development_at_Public_Campuses_in_Nepal

Tsui, A.B. (2005). Expertise in teaching: Perspectives and issues. In K. Johnson (ed), Expertise in second language learning and teaching, (pp.167-189). New York: Palgrave Macmillan.

Villegas-Reimer, E. (2003). Teacher professional development: an international review of the literature. Paris: International Institute for Educational Planning. Retrieved from http://unesdoc.unesco.org/ images/0013/001330/133010e.pdf

\section{Citation of this Article:}

Joshi, D. K., Gnawali, L., \& Dixon, M. (2018). Experience of professional development strategies: Context of Nepalese EFL teachers.

Pakistan Journal of Education, 35(2), 53-78.

Received on: March

07,2018

Revised on: June

12,2018

Accepted on: July

02,2018 